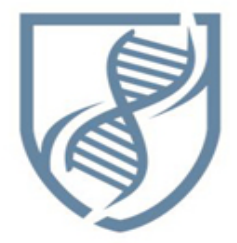

Journal of Bioscience and Applied Research

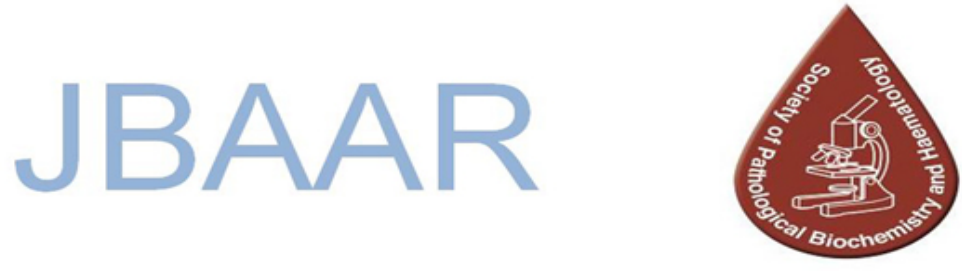

WWW.JBAAR.ORG

\title{
Biochemical effects of some insect growth regulators and bioinsecticides against cotton leafworm, Spodoptera littoralis (Boisd.)(Lepidoptera: Noctuidae)
}

\author{
Assar,A.A. ${ }^{\text {; }}$ Abo El-Mahasen,M.M. ${ }^{\text {; }}$ Dahi,H.F. ${ }^{2}$; Amin,H.S. ${ }^{2}$ \\ 1-Zoology.Dep., Faculty of Science, Minoufiya Univ., Shebien El-Kom \\ 2-Plant Protection Research Institute, Agricultural Research Center, Dokki, Egypt \\ (Corresponding author email : abadaassar@yahoo.com)
}

\begin{abstract}
The current work was carried out to evaluate the decreased with hexaflumuron and biochemical effects of $\mathrm{LC}_{50}$ of four compounds; emamectin Phenoloxidase and Chitinase activity and spinetoram as bioinsecticides, hexaflumuron and increased with all tested insecticides. teflubenzuron as Insect growth regulators (IGR's) against the $4^{\text {th }}$ instar larvae of Spodoptera littoralis to determine the effects of these compounds on total carbohydrates, proteins, lipids, acetylcholinesterase, chitinase, phenoloxidase, carbohydrates hydrolyzing enzymes, nonspecific esterases, phosphatases and transaminase enzymes. The obtained results indicated that total proteins and lipids content were significantly decreased with all tested insecticides, except slightly increase in total protein with spinetoram, in contrast, all tested insecticides led to an increase in total carbohydrates. The tested insecticides significantly increased the invertase activity except emamectin decreased the enzyme activity. A significant decrease in the activity of trehalase and amylase activity was induced by the tested insecticides, except with emamectin and teflubenzuron in case of amylase. The tested insecticides significantly decreased the activity of acid (AcP) and alkaline (AlP) phosphates. It is clearly noticed that teflubenzuron and spinetoram significantly increased alpha esterases in contrast, decreased with hexaflumuron and emamectin. A highly significant decreased in beta esterases was induced by teflubenzuron and hexaflumuron and increased with spinetoram and emamectin. All tested insecticides induced a significant inhibitory effect on aspartate aminotransferase (AST) and alanine aminotransferase (ALT) activity except with teflubenzuron.

Acelylcolinesterase (AchE) activity significantly increased with emamectin and teflubenzuron while

Keywords: IGRs, Acid phosphatase, Alkaline phosphatase, Aspartate aminotransferase, Alanine aminotransferase, Acetylcholinesterase.

\section{Introduction}

The cotton leafworm S. littoralis is one of the most destructive pests in the tropical and subtropical areas of the world (Hill, 1987). It attacks plants in 44 families containing at least 112 species of plants of varying economic importance (Sarto and Monteys, 1988).

Over the last few decades, the intensive use of broadspectrum insecticides against the Egyptian cotton leafworm, $S$. littoralis has led to the development of resistance to many registered pesticides making their control even more difficult (Miles and Lysandrou, 2002; Aydin and Gurkan, 2006). Insect growth regulators (IGR's) is considered as the possible alternative way of conventional synthetic insecticides for controlling this pest (Raslan, 2002). They have novel mode of action which disrupt the physiology and development of the target pest. Such compounds tend to be selective and generally less toxic to non-target organisms than conventional insecticides (Gurr et al., 1999). Depending on the mode of action, IGR's had been recently grouped in chitin synthesis inhibitors (CSIs) and substances that interfere with the action of insect hormones (i.e. juvenile hormone analogues, and ecdysteroids) (Tunaz and Uygun, 2004). CSIs interfere
\end{abstract}


with chitin biosynthesis in insects (Gijswijt et al., 1979) and thus prevent moulting, or produce an imperfect cuticle (Hammock and Quistad, 1981). They also affect the hormonal balance in insects, thereby resulting in different physiological disturbances (Soltani et al., 1984). These compounds have no appreciable effects on parasitoids and has probably a mild effect on other natural enemies (Ishaaya et al., 2002). Also, it has low mammalian toxicity (Barazani, 2001). The present work was carried out to evaluate the biochemical effects of $L_{50}$ of four compounds; emamectin and spinetoram as bioinsecticides, hexaflumuron and teflubenzuron as Insect growth regulators (IGR's) against the $4^{\text {th }}$ instar larvae of Spodoptera littoralis.

\section{Materials and Methods}

\section{Rearing technique:}

Eggs of the cotton leafworm $S$. littoralis were obtained from laboratory strain maintained at the cotton pest research department, Plant Protection Research Institute, Agricultural Research Center, Dokki; Giza. These eggs were kept in glass jar covered with gauze under laboratory condition of $27 \pm 2{ }^{\circ} \mathrm{C}$ and $65 \pm 5 \%$ R.H. until hatching. The larvae were reared on fresh leaves of castor bean Ricinus commanis till the fourth larval instar described by (Ghoneim, 1985).

\section{2- Bioinsecticides tested:}

\subsection{Spinetoram (Radiant $12 \%$ SC)}

Major component (3'ethoxy, 5,6-dihydro spinosyn J):(2R,3aR,5aR,5bS,9S,13S,14R,16aS,16bR)-13$\{[(2 \mathrm{~S}, 5 \mathrm{~S}, 6 \mathrm{R})-5$-(dimethylamino)-6-methyltetrahydro2Hpyran- 2-yl]oxy\}-9-ethyl-14-methyl-7,15-dioxo2,3,3a,4,5,5a,5b,6,7,9,10,11,12,13,14,15,16a,16boctadecahydro-1H-as-indaceno[3,2-d]oxacyclododecin-2-y 6-deoxy-3-O-ethyl-2,4-di-O-methyl-beta-Lmannopyranoside was obtained from Dow Agro Sciences,Egypt

\subsection{Emamectin benzoate (Emaskem 1.9\%EC)}

Emamectin benzoate consists of a mixture of at least 90\% 4"-epi-methylamino-4"-deoxyavermectin B1, and a maximum of $10 \% \quad 4$ "-epi-methylamino-4"deoxyaverrnectin Blb benzoate was obtained from Egypt Agricultural Development

\subsection{Hexaflumuron (Cameron 10\%EC)}

Hexaflumuron is a benzoylphenyl urea-type insecticide and is the common name for $\mathrm{N}-(((3,5-$ dichloro4-(1,1,2,2-tetrafluoro-ethoxy)phenyl)amino)carbonyl)-2,6difluorobenzamide was obtained from Cam Agricultural Chemicals

\subsection{Teflubenzuron (Nomolt $15 \%$ SC)}

IUPAC:1-(3,5-dichloro-2,4-difluorophenyl)-3(2, difluorobenzoyl) ureaCA:N-[[(3,5-dichloro2,4difluorophenyl)amino]carbonyl]-2,6-difluorobenzamide was obtained from Basev Limited ,Egypt

\section{3-Biochemical studies:}

The following biochemical studies were carried out for the $4^{\text {th }}$ instar larvae of $S$. littoralis following their treated with the $\mathrm{LC}_{50}$ of each of the tested insecticides.

\section{- Preparation of insects for analysis:-}

The insects were prepared as described by (Amin, 1998). They were homogenized in distilled water $(50 \mathrm{mg} / 1$ $\mathrm{ml}$ ). Homogenates were centrifuged at 8000 r.p.m. for 15 min at $2{ }^{\circ} \mathrm{C}$ in a refrigerated centrifuge. The deposits were discarded and the supernatants, was stored at least one week without appreciable loss of activity when stored at $5^{0} \mathrm{C}$.

1.Total carbohydrates were determined according to (Dubois et al., 1956)

2.Total proteins were determined according to (Bradford, 1976)

3.Total lipids were determined according to (Knight et al., 1972 )

4. Digestive enzymes were determined according to (Ishaaya and Swirski, 1976)

5.Acetylcholinesterase was determined according to (Simpson et al.,1964)

6.Chitinase activity was determined according to (Bade and Stinson, 1981)

7. $\alpha$ - and $\beta$-esterases were determined according to (Van Asperen, 1962)

8.Phenoloxidase was determined according to (Ishaaya, 1971)

9.Phosphatases were determined according to (Powell and Smith, 1954)

10.Transaminases were determined according to (Reitman and Frankle, 1957)

4-Statistical analysis:

The results of biochemical determinations were pooled from triplicate determinations. The results were analyzed by one - way analysis of variance (ANOVA) using constant statistical software (cohort software, Berkeley). When the ANOVA statistics were significant (P $<0.01$ ), means were compared by the Duncan's multiple range test.

\section{Results and Discussion}

1-Effect of tested insecticides on total carbohydrates, proteins and lipids

Results given in Table (1) indicated that all tested insecticides led to increase in total carbohydrates which more obvious with emamectin compared with control. Total carbohydrates content were 7.45, 7.14, 7.17 and 6.69 (mg/g.b.wt) for emamectin, spinetoram, hexaflumuron and teflubenzuron, respectively, while it was 6.54 (mg/g.b.wt) with control.

Carbohydrates play a major role in insect development like metabolism, metamorphosis, development of flight muscles, reproduction and embryonic development (Chapman, 1998).

The total haemolymph protein content of $4^{\text {th }}$ instars of $S$. littoralis was decreased with all tested insecticides. The total protein were 30.3, 27.9 and 26.9 (mg/g.b.wt) with emamectin, hexaflumuron and teflubenzuron respectively, except increase with spinetoram 36.8 (mg/g.b.wt) as compared with control 35.7 (mg/g.b.wt). This increase may be due to the natural increase of protective hydrolytic and 
detoxifying enzymes that usually take place shortly after treatment.

Similar results were obtained by (Mostafa, 1993) and (Sokar, 1995) for the total haemolymph protein of the same species treated with triflubenuron and hexaflumuron, respectively. Different results were obtained by (El-Barky et al., 2008) stated that total proteins significantly decreased using spinetoram on S.littoralis. The protein pool of the haemolymph functions as a reserve source of protein synthesis need for growth and development of the adult stage during pupal life (Florkin and Jeanuiaux, 1964).

Wilkinson (1976) stated that protein help to synthesize microsomal detoxifying enzymes which assist in the detoxificaition of toxicants that enter into the insect

Table (1): Effect of $\mathrm{LC}_{50}$ of the tested insecticides on the total carbohydrates, proteins and lipids on $4^{\text {th }}$ instar larvae of $S$. littoralis after 3 days of treatment

\begin{tabular}{|c|c|c|c|}
\hline \multirow{2}{*}{ Insecticides } & Total Carbohydrates & Total Proteins & Total Lipids \\
\cline { 2 - 4 } & $\mathbf{( m g / m l )} \pm \mathbf{S E}$ & $\mathbf{( m g / g m ~ t i s s u e ) ~} \pm \mathbf{~ S E}$ & (mg/gm tissue) $\pm \mathbf{S E}$ \\
\hline control & $6.54 \pm 0.1$ & $35.7 \pm 0.6$ & $3.9 \pm 0.09$ \\
\hline emamectin & $7.45 \pm 0.07$ & $30.3 \pm 0.4$ & $2.8 \pm 0.09$ \\
\hline spinetoram & $7.14 \pm 0.09$ & $36.8 \pm 0.7$ & $3.5 \pm 0.09$ \\
\hline hexaflumuron & $7.17 \pm 0.09$ & $27.9 \pm 0.6$ & $3.2 \pm 0.05$ \\
\hline teflubenzuron & $6.69 \pm 0.04$ & $26.9 \pm 0.8$ & $3.3 \pm 0.08$ \\
\hline F value & $23.6 *$ & $33.7 *$ & $40 *$ \\
\hline
\end{tabular}

*: significant

\section{2-Effect on carbohydrates hydrolyzing enzyme}

Three digestive enzymes; amylase, trehalase and invertase were determined in $4^{\text {th }}$ instar larvae of $S$. littoralis which treated with $\mathrm{LC}_{50}$ of the tested insecticides. Data in table (2) showed that increased the invertase activity which was 332, 319.3 ( $\mu$ g glucose /g.b.wt) with spinetoram, teflubenzuron, respectively, except with emamectin which exhibited decreased the enzyme activity was 299.3 while it was 313 with control.

Also data in (Table 2) showed that a significant decrease in the activity of trehalase was induced by the tested insecticides spinetoram, hexaflumuron, Teflubenzuron, the values were 118.7, 118 and 109.3( $\mu \mathrm{g}$ glucose /g.b.wt), respectively, except increase with emamectin 131.7. as compared with control 121( $\mu$ g glucose /g.b.wt). Furthermore, the activity of amylase was high in case of emamectin 78.7 followed by hexaflumuron 74 than other compounds which teflubenzuron caused inhibition of the activity of amylase 45.3 as compared with control 52.3( $\mu$ g glucose /g.b.wt).

Similar findings were also reported by El-Barky et al. (2008) and Rashwan(2013) using spinetoram on S.littoralis with trehalase and amylase; (El-Sheikh et al., 2013) Using teflubenzuron with fluctuated changes in trehalase on S.littoralis.The rapid decrease of glucose concentration at the end of last larval instar of the cotton leafworm, $S$. Littoralis was probably caused by high metabolic activity of the epidermis, which is known as a tissue with low body. Proteins are the most important components of biochemical of insect that bind the foreign compounds. In general, the problem of protein synthesis is intimately related to metabolism of nucleic acids.

All tested insecticides led to decrease in lipids which more obvious with emamectin than other compounds. It was 2.8, 3.5, 3.2 and 3.3 (mg/g.b.wt) for emamectin, spinetoram, hexaflumuron and teflubenzuron, respectively, as compared with control 3.9 (mg/g.b.wt). Hill and Izatt (1974) reported that lipid accumulation is more likely to be related directly to lack of juvenile hormone. The administration of tested insecticide does not act on the site of secretion of juvenile hormone, i.e., corpora allata. trehalase, so it is unable to utilize trehalose (Florkin and Jeanuiaux, 1964)

\section{3-Effect on phosphatase enzymes}

The data in Table (3) showed that the all tested insecticide significantly decreased the activity of alkaline phosphatase (AlP) as compared with control, hexaflumuron gave a lowest decrease (248.7 Ux10 $/$ g.b.wt) followed by emamectin, teflubenzuron and spinetoram (309.7, 310 and $445.7 \mathrm{Ux} 10^{3} / \mathrm{g}$. b.wt), respectively, as compared with control (611 Ux10/g.b.wt).

The tested insecticides also caused inhibition in the activity of acid phosphatase (AcP) as compared with control (Table 3), hexaflumuron and teflubenzuron induced more inhibition in the activity of acid phosphatase (58.2 and $63.2 \mathrm{Ux} 10^{3} /$ g.b.wt) respectively, than emamectin and spinetoram (66.5 and $\left.73.9 \mathrm{Ux} 10^{3} / \mathrm{g} . \mathrm{b} . \mathrm{wt}\right)$ respectively, as compared with control (84.2 Ux10\%3.b.wt).

These results are in agreement with those obtained on S.littoralis by [(El-Barky et al., 2008) and (El-Sheikh, 2012)] using spinetoram with significant decrease in both acid and alkaline phosphatases. On the other hand, some increase in the activity of acid phosphatase in the same insect by (Sokar, 1995) using hexaflumuron.

Sridhara and Bhat (1963) stated that the increase or decrease of both phosphatase enzymes development is reflected in increase or decrease in acid-soluble phosphorus content. 
Table (2): Effect of $\mathrm{LC}_{50}$ of the tested insecticides on the carbohydrates hydrolyzing enzymes on $4^{\text {th }}$ instar larvae of $S$. littoralis after 3 days of treatment

\begin{tabular}{|c|c|c|c|}
\hline \multirow{2}{*}{ Insecticides } & Invertase & Trehalase & Amylase \\
\cline { 2 - 4 } & \multicolumn{2}{|c|}{ Mean enzyme activity (ug glucose /g.b.wt) \pm SE } \\
\hline control & $313 \pm 3.8$ & $121 \pm 2.2$ & $52.3 \pm 1.7$ \\
\hline emamectin & $299.3 \pm 3.6$ & $131.7 \pm 4.1$ & $78.7 \pm 1.5$ \\
\hline spinetoram & $332 \pm 3.3$ & $118.7 \pm 0.9$ & $51.7 \pm 0.9$ \\
\hline hexaflumuron & $313.7 \pm 1.2$ & $118 \pm 2.1$ & $74 \pm 0.9$ \\
\hline teflubenzuron & $319.3 \pm 1.8$ & $109.3 \pm 2.3$ & $45.3 \pm 1.5$ \\
\hline F value & $10.74^{*}$ & $6.6 *$ & $99.4 *$ \\
\hline
\end{tabular}

*: significant

Table (3): Effect of $\mathrm{LC}_{50}$ of the tested insecticides on the activity of phosphatase (AcP and AIP) on $4^{\text {th }}$ instar larvae of $S$. littoralis after 3 days of treatment

\begin{tabular}{|c|c|c|}
\hline \multirow{2}{*}{ Insecticides } & Alkaline phosphatase & Acid phosphatase \\
\hline & \multicolumn{2}{|c|}{ Mean enzyme activity $\left(U^{*} 10^{n} /\right.$ g.b.wt $) \pm S E$} \\
\hline control & $611 \pm 5.4$ & $84.2 \pm 2.5$ \\
\hline emamectin & $309.7 \pm 3.5$ & $66.5 \pm 1.5$ \\
\hline spinetoram & $445.7 \pm 5.9$ & $73.9 \pm 1.0$ \\
\hline hexaflumuron & $248.7 \pm 3.3$ & $58.2 \pm 1.2$ \\
\hline teflubenzuron & $310 \pm 7.8$ & $63.2 \pm 1.1$ \\
\hline F value & $532.6 * *$ & $30.9 *$ \\
\hline
\end{tabular}

*: significant $* *$ : highly significant

\section{4-Effect on $\alpha$ - and $\beta$-esterases}

Values of alpha and beta esterases are tabulated in Table (4). Alpha esterases was activated with spinetoram (1488 ug $\alpha$ - naphthol/min/g.b.wt) as compared with control 1366.7 and activation occur with emamectin 388.3 in case of beta esterases, while it was 327 ug $\alpha$ naphthol/min/g.b.wt with control. In both alpha and beta esterases is highly inhibited with hexaflumuron 807 and $171.7 \mathrm{ug}$ ( $\alpha$ - naphthol/min/g.b.wt), respectively.

It is clearly noticed that IGR's may be cause different levels of significant changes in alpha and beta esterases on S.littoralis (Bakr et al., 2013), spinetoram slightly increased compared with control in case of alpha esterases (Rashwan, 2013) and emamectin highly increased in case of beta esterases. 
Table (4): Effect of $\mathrm{LC}_{50}$ of the tested insecticides on the activity of $\alpha$-and $\beta$ - esterases on $4^{\text {th }}$ instar larvae of $S$. littoralis after 3 days of treatment

\begin{tabular}{|c|c|c|}
\hline \multirow{2}{*}{ Insecticides } & Alpha esterase & Beta esterase \\
\cline { 2 - 3 } & Mean enzyme activity (ug $\boldsymbol{\alpha}$-or $\boldsymbol{\beta}$-naphthol/min/g.b.wt) \pm SE \\
\hline control & $1366.7 \pm 12.9$ & $327 \pm 4.6$ \\
\hline emamectin & $1268 \pm 14.1$ & $388.3 \pm 4.8$ \\
\hline spinetoram & $1488 \pm 13.6$ & $329 \pm 1.4$ \\
\hline hexaflumuron & $807 \pm 9.2$ & $171.7 \pm 3.1$ \\
\hline teflubenzuron & $1377 \pm 7.4$ & $250.7 \pm 6.8$ \\
\hline F value & $602.1 * *$ & $216.3 * *$ \\
\hline
\end{tabular}

**: highly significant

\section{5-Effect on transaminases enzymes}

The obtained results (Table 5) revealed that all tested insecticides induced a significant inhibitory effect on aspartate aminotransferase (AST) activity were 5730, 7033.3, 5960 and 5126.7 (Ux103\% g.b.wt) for emamectin, reduced both GOT and GPT. On the other hand, (Mostafa, spinetoram, hexaflumuron and teflubenzuron, respectively, 1993) reported a decrease in GPT activity and an increase while it was 7510 with control. Also inhibition occurs in in GOT activity of haemolymph $4^{\text {th }}$ larval instar of $S$. alanine aminotransferase (ALT) activity except activation Littoralis after treatment with hexaflumuron. Emamectin occur with teflubenzuron (3676.7 Ux10\%3.b.wt) as on the same insects increased both GOT and GPT Abd Elcompared with control 3556.7 (Ux10³/g.b.wt).
It is clearly noticed that pronounced inhibition of AST compared with control in the same insect by (Abd ElHafez and Osman (2013).

Table (5): Effect of $\mathrm{LC}_{50}$ of the tested insecticides on the activity of transminases on $4^{\text {th }}$ instar larvae of $S$. littoralis after 3 days of treatment

\begin{tabular}{|c|c|c|}
\hline \multirow{2}{*}{ ALT(GPT) } & AST(GOT) & \multirow{2}{*}{ Insecticides } \\
\cline { 1 - 2 } Mean enzyme activity $($ UX10 $/$ g.b.wt) \pm SE & \multirow{2}{*}{ control } \\
\hline $3556.7 \pm 119.4$ & $7510 \pm 211.4$ & emamectin \\
\hline $3106.7 \pm 84.4$ & $5730 \pm 83.8$ & spinetoram \\
\hline $3393.3 \pm 56.2$ & $7033.3 \pm 125.3$ & hexaflumuron \\
\hline $2766.7 \pm 58.2$ & $5960 \pm 100.3$ & teflubenzuron \\
\hline $3676.7 \pm 93$ & $5126.7 \pm 124.4$ & F value \\
\hline $10.96 *$ & $30.5 *$ & \\
\hline
\end{tabular}

\footnotetext{
*: significant
} 
6-Effect on acelylcolinesterase, chitinase and pronounced increase in activity of chitinase; fluctuated phenoloxidase changes recorded in chitinase by (El-Sheikh et al., 2013)

Acelylcolinesterase (AchE) was tabulated in Table (6) which significantly activated with emamectin and teflubenzuron 427.3 and 310 (ug AchBr/min/g.b.wt), respectively, while it was inhibited with hexaflumuron and spinetoram 209.7 and 224.7, respectively, as compared with control 231.7(ug AchBr/min/g.b.wt).

Similar findings were also reported in the same insect by (Abd El- Mageed and Shalaby, 2011) using IGR's. Reduction in acetylcholinesterase appeared (Mostafa, 1993) using teflubenzuron. On other hand spinetoram induced moderate increase in activity of acetylcholinesterase by [(El-Barky et al. (2008), Fahmy and Dahi (2009) and Rashwan, (2013).

Chitinase values were 1853, 1993.3, 1270.3 ( $\mu$ g NAGA/min/g.b.wt) with emamectin, spinetoram and hexaflumuron, respectively, and slightly decreased with teflubenzuron 1203.3, while it was 1238 with control ( $\mu \mathrm{g}$ NAGA/min/g.b.wt).

These results are in agreement with those obtained on haemolymph Revenis (2011)

S.littoralis by (Rashwan, 2013) using spinetoram stated that

Table (6): Effect of $\mathrm{LC}_{50}$ of the tested insecticides on the activity of acetylcolinesterase, chitinase and phenoloxidase on $4^{\text {th }}$ instar larvae of $S$. littoralis after 3 days of treatment

\begin{tabular}{|c|c|c|c|}
\hline phenoloxidase & Chitinase & AchE & \\
\hline $\begin{array}{c}\text { Mean enzyme activity } \\
\text { (O.D. units/min/g.b.wt) } \pm \\
\text { SE }\end{array}$ & $\begin{array}{c}\text { Mean enzyme activity } \\
\text { ( } \mu \text { g NAGA/min/g.b.wt) } \\
\pm \text { SE }\end{array}$ & $\begin{array}{c}\text { Mean enzyme activity } \\
\text { ( } \mu \mathrm{g} \text { AchBr/min/g.b.wt) } \\
\pm \mathrm{SE}\end{array}$ & \\
\hline $11 \pm 0.3$ & $1238 \pm 16.8$ & $231.7 \pm 4.9$ & control \\
\hline $16.9 \pm 0.9$ & $1853 \pm 20.7$ & $427.3 \pm 11.4$ & emamectin \\
\hline $18.5 \pm 0.6$ & $1993.3 \pm 28.3$ & $224.7 \pm 2.4$ & spinetoram \\
\hline $14.6 \pm 0.4$ & $1270.3 \pm 4.7$ & $209.7 \pm 4.5$ & hexaflumuron \\
\hline $11.3 \pm 0.2$ & $1203.3 \pm 5.5$ & $310 \pm 10.3$ & teflubenzuron \\
\hline $33.9 * *$ & $248.99 * *$ & $80.7 *$ & F value \\
\hline
\end{tabular}

*significant $* *$ : highly significan

\section{References}

Abd EL-Aziz, H. S. (2014). Effect of some littoralis (Boisd.). and Albino rat. Egypt. Acad. J. Biol. insecticides on certain enzymes of Spodoptera littoralis Sci., 6 (3): 59-68.

(Boisd.). Egypt. J. Agric. Res., 92 (2):58-71.

Abd El-Mageed, A. E. and Shalaby, S. E.

Abd El-Hafez, H. F. and Osman, H. H. (2013). (2011).Toxicity and biochemical impacts of some new Effects of pyridalyl and emamectin benzoate on some insecticide mixtures on cotton leafworm, Spodoptera biological and biochemical parameters of Spodoptera littoralis (Boisd.). Plant Protect. Sci., 47: 166-175. 
Amin, T. R. (1998). Biochemical and endocrine and reproductive systems of the cotton leafworm, physiological studies of some insect growth regulators on Spodoptera littoralis (Boisd.) (Lepidoptera: Noctuidae). the cotton leafworm, Spodoptera littoralis (Boisd.) .Ph.D. Ph.D. Thesis, Fac. of Sci., Al-Azhar Univ., Cairo, Egypt.

Thesis, Faculty of Science, Cairo Univ. Egypt.

Amin, T. R. and Fahmy, N. M. (2011).Impact of spinetoram on some nitrogenous components related to protein metabolites in the cotton leafworm, Spodoptera littoralis (Boisd.). Egypt. Acad. J. Biol. Sci., 3(1):51-64.

Aydin, M. H. and Gurkan, M. O. (2006). The efficacy of spinosad on different strains of Spodoptera littoralis (Boisd.) (Lepidoptera: Noctuidae). Turkish J. Biol.; 30 (1): 5-9.

Bade, M. L. and Stinson, A. (1981). Biochemistry of insect differentiation. A system for studying the mechanism of chitinase activity in vitro. Archs Biochem. Biophys.; 206: 213-221.

Bakr, R. F.; Hafez, J. A.; Khamiss, O. A. and Zyaan, O. H. (2013). Biochemical studies on the effect of chitin synthesis inhibitor, (flufenoxuron) and SpliMNPV on Press.

the cotton. Egypt. Acad. J. Biol. Sci., 6(2): 29 -38.

Barazani, A. (2001). Rimon, an IGR insecticide. Phytoparasitica, 29: 59-60.

Bradford, M. M. (1976). A rapid and sensitive method for the quatitation of microgram quantities of protein utilizing the principle of protein-dye binding. Anal. Biochem., 72: 248-254.

Chapman, R. F. (1998). The insects: structure and function. Cambridge Univ. press, Cambridge, UK, 770 pp.

Dubios, M. ; Gilles, K. A.;Hamilton, J. K.; Rebers, P. A. and Smith, F. (1956). Colorimetric method for determination of sugars and related substances. Analyt.Chem., 28:350-356.

El-Barky, N. M.; Dahi, H. F. and El-Sayed, Y. A. (2008). Toxicicological evaluation and biochemical impacts for radiant as a new generation of spinosyn on Spodoptera littoralis (Boisd.) larvae. Egypt. Acad. J. Biol. Sci., 1(2): 85 - 97.

El- Sheikh, E. A. (2012). Biological, biochemical and histological effects of spinosad, Bacillus thuringiensis var. kurstaki and cypermethrin on the cotton leafworm, Spodoptera littoralis (Boisd.). Egypt. Acad. J. Biol. Sci., 4 (1) 113-124.

El-Sheikh, T. A.; Rafea, H. S.; El-Aasar, A. M. and Ali, S. H. (2013). Biochemical studies of Bacillus thuringiensis var.kurstaki, Serratia marcescns and teflubenzurone on cotton leafworm, Spodoptera littoralis (Boisd.) (Lepidoptea: Noctuidae) . Egypt. Acad. J. Biol. Sci., 5 (1):19-30.

Fahmy, N. M.; and Dahi, H. F. (2009). Changes in detoxifying enzymes and carbohydrate metabolism associated with spinetoram in two field-collected strains of Spodoptera littoralis (Boisd.). Egypt. Acad. J. Biol. Sci., 1 (1): $15-26$.

Florkin, M. and Jeanuiaux, C. H. (1964). Haemolymph composition. In "Physiology of Insecta": (Edited by Rockstein, M.). Academic Press, New York \& London., (3): 109-152.

Ghoneim, K. S. (1985). Physiological studies on
Gijswijt, M. J.; Deul, D. H. and DeJong, B. J. (1979). Inhibition of chitin synthesis by benzoylphenylurea insecticides, III. Similarity in action in Pieres brassicae (L.) with polyxin D. Pestic. Biochem. Physiol., 12:84-94.

Gurr, G. M.; Thwaite, W. G. and Nicol, H. I. (1999). Field evaluation of the effects of the insect growth regulator (tebufenozide) on entomophagous arthropods and pests of apples. Austr. J.Entomol., 38: 135-140.

Hammock, C. D. and Quistad, G. B. (1981).Metabolism and mode of action of juvenile hormone, juvenoids and other insect growth regulators. In: "Progress in pesticide Biochemistry" (Hutson, D.H. and Roberts, T.R. eds.). John Wiley \& Sons Ltd., (1): 1-85

Hill, D. S. (1987). Agricultural insect pests of temperate regions and their control. Cambridge University

Hill, L. and Izatt, E. G. (1974). The relationships between corpora allata and fat body and hemolymph lipids in the adult female desert locust. J. Insect Physiol., 20: 2143-2156

Ishaaya , I. (1971). Observation on the phenoloxidase system in the armored scale Aonidiella aurantii and Chrysomphalus aonidum . Comp. Biochem . Physiol ., 39 B , 935-943.

Ishaaya, I.; Horowitz, A. R.; Tirry, L. and Barazani, A. (2002). Novaluron (Rimon), a novel IGRMechanism, selectivity and importance in IPM programs. $54^{\text {th }}$ Intern. Symp. on Crop Protection, Part II, Gent, Belgium, 67 (3): 617-626.

Ishaaya, I. and Swirski, E. (1976). Trehalase, invertase and amylase activities in the black scale Saissetia oleae, and their relation to host adaptability. J. Insect Physiol. 22: 1025-1029.

Knight, J. A.; Anderson, S. and Rawle, J. M. (1972). Chemical basis of the sulfophospho-vanillin reaction for estimating total serum lipids. Clin. Chem., 18: 199-202.

Miles, M.; and Lysandrou, M. (2002). Evidence for negative cross resistance to insecticides in field collected Spodoptera littoralis (Boisd.) from Lebanon inlaboratory bioassays. Mededelingen (Rijksuniversiteitte Gent. Fakulteit van de LandbouwkundigeenToegepaste Biologische Wetenschappen), 67: 665.

Mostafa, S. A. (1993). Biochemical effect of some chemical compounds on Spodoptera littoralis (Boisd.). Ph.D. Thesis, Fac. Agric., Al-Azhar Univ., Egypt.

Powell, M. E. and Smith M. J. (1954). The determination of serum acid and alkaline phosphatase activity with 4- aminoantipyrine . J.Clin. Pathol . ,7 : 245248 .

Rashwan M. H. (2013). Biochemical Impacts of rynaxypyr (coragen) and spinetoram (radiant) on Spodoptera littoralis (Boisd.). Nat. Sci ; 11(8):40-47.

Raslan, S. A. (2002). Preliminary report on initial and residual mortality of the natural product, spinosad, for 
controlling cotton leafworm egg masses. In: Egypt. $2^{\text {nd }}$ Inter. Conf., Plant Prot. Res. Inst., Cairo, Egypt, 1: 635637.

Reitman, S. and Frankel, S. (1957). Colourimetric method for aspartate and alanine transaminases. Amer. J. Clin. Pathol., $28: 56$.

Revenis, C. E. (2011). Role and importance of phenoloxidase in insect hemostasis. J. Innate. Immun.;3(1): 28-33.

Sarto, I. and Monteys, V. (1988). Lepidopterous species recognised as pests in Catalina and the affected crops. Resumnese I JournadaIberica de Lepidopterologia Madrid 19 Nov.

Simpson, D. R.; Bull D. L. and Lindquist, D. A (1964). A semimicro technique for the estimation of cholinesterase activity in bollweevil. Ann. Entomol. Soc. Amer., 57 (3): 367- 377.

Sokar, L. A. (1995). Possible alternatives to classical insecticides in management program of Spodoptera littoralis (Boisd.). Ph. D. Thesis, Zagazig Univ., Egypt.
Soltani, N.; Besson, M. T. and Delachambre, J. (1984). Effects of diflubenzuron on the pupal-adult development of Tenebrio molitor (L.) (Coleoptera: Tenebrionidae): growth and development cuticle secretion, epidermal cell density, and DNA synthesis. Pestic. Biochem. Physiol., 21:256-264.

Sridhara, S. and Bhat, J. V. (1963). Alkaline and acid phosphatases of the silkworm, Bombyx mori L. J. Insect Physiol., 9: 693-701.

Tunaz, H. and Uygun, N. (2004). Insect growth regulators for insect pest control. Turkish J. Agricultural. Forestry, 28: 337-387.

Van Asperen, K. (1962). A study of housefly esterase by means of sensitive colourimetric method. J. Insect Physiol., 8: 401-416.

Wilkinson, F. (1976). Insecticide biochemistry and physiology. Plenum Press, New York. 